\title{
Why Should Physicians Care about Hospital Mergers and Acquisitions?
}

\author{
Satiani $B^{1 *}$ and \\ Patrick S Vaccaro ${ }^{2}$
}

Received: May 29, 2017; Accepted: June 24, 2017; Published: June 30, 2017

Mergers and acquisitions (M\&A) have long been part of the healthcare landscape. The purported goals include efficiency, better access, improved quality and lower cost leading to enhanced profitability [1]. The uncertainty in the healthcare environment and reimbursement has led health systems to pursue $M \& A$ to preserve their competitive position and to gain price leverage with insurers. For others, it may mean accessing population health expertise, health plans or association with a high profile health system.

But, is it good for patients as consumers, their physicians and for the United States?

The Advisory Board reports that the volume of M\&As almost doubled from 50 in 2009 to 89 in 2012 [2]. Indeed, hospital transactions as a whole (including mergers, acquisitions, and joint ventures) have climbed from 66 in 2010 and 95 in 2014 to 112 in 2015, an 18\% increase from 2014 [3]. Kaufman, Hall \& Associates reported 102 deals in 2016 and reported an 8\% increase in the first quarter of 2017 compared to the same period in 2016 [4]. It is projected that one in five hospitals will pursue a merger in the next five years [5]. The majority of mergers occur in hospitals with less than $\$ 500$ million in annual revenue and in not-forprofits, which represent about $75 \%$ of all hospitals. Forty one per cent of 250 senior healthcare executives surveyed expect that $M \& A$ will represent their growth strategy in the coming year [6].

One of the biggest reasons advanced for $M \& A$ is increasing 'efficiency' and achieving cost savings through 'economies of scale.' Consolidation of administrative services, personnel, laboratories and clinical services and renegotiating vendor contracts or efficiencies in supply chain management sound attractive. The cost of information technology, accounting and legal services, and expense of recruiting specialists can be amortized across the hospitals in the merging health systems. However, in recent years, governmental agencies such as the Federal Trade Commission (FTC) and the courts have generally regarded these claims as speculative barring empirical data.

\section{Antitrust Concerns}

The government agency charged with protecting consumers and policing monopolistic behavior or price fixing is the FTC. The antitrust statutes utilized by the FTC are the Sherman and the Clayton Act [7]. The FTC has recently challenged monopolistic behavior of the healthcare industry by questioning not only horizontal or vertical hospital mergers but physician employment where
1 Department of Surgery, Clinical Surgery, Division of Vascular Diseases \& Surgery, Associate Director FAME; Director Faculty Leadership Institute Medical Director Vascular Labs, The Ohio State University College of Medicine Columbus, USA

2 Department of Surgery, Division Chief Division of Vascular Diseases \& Surgery, The Ohio State University College of Medicine Columbus, USA

\section{*Corresponding author: Satiani B \\ ” bhagwan.satiani@osumc.edu}

Professor of Clinical Surgery, Department of Surgery, Division of Vascular Diseases \& Surgery, Associate Director FAME; Director Faculty Leadership Institute Medical Director Vascular Labs, The Ohio State University College of Medicine Columbus, St\# 700376 W. 10th Avenue, Columbus, $\mathrm{OH}$ 4321043210 , Ohio, USA.

Tel: +1 614-292-7137

Citation: Satiani B, Vaccaro PS (2017) Why Should Physicians Care about Hospital Mergers and Acquisitions?. J Hosp Med Manage. Vol. 3 No. 1: 7

Metropolitan Statistical Areas are already 'highly concentrated.' Market concentration is measured by the Herfindahl-Hirschman Index $(\mathrm{HHI})$, which is calculated by squaring the market share of each firm competing in the market and then summing the resulting numbers [8]. Insurers have also pushed back against potential market price increases that occur after mergers.

Several high profile mergers have been rejected by the FTC including Penn State Hershey Medical Center's proposed merger with Pinnacle Health System, Carolinas Healthcare, Advocate Healthcare (still in litigation) and Promedica in Toledo, Ohio. The FTC expressed concern that the merged systems would control $>50 \%$ of the post-merger market, which could lead to reduced competition, greater costs and possibly lower quality of care. 


\section{Are Healthcare Costs Lowered and Quality Improved by Mergers?}

Earlier reports suggested that cost and price growth were somewhat lower for merging hospitals compared to non-merging hospitals when followed longitudinally [9]. Antwi and colleague suggested that although rates of price growth are higher in monopolistic markets, there is no correlation between a change in hospital concentration and price growth [10].

However, evidence is accumulating that mergers leading to larger health systems may in fact lead to costlier care and patient care provided by hospital employed physicians may be more expensive [11]. Gaynor and Town reviewed the literature and concluded that horizontal mergers (or hospital consolidation within a specific geographic and product area) generally led to higher prices [12]. Prices increased almost $20 \%$ in concentrated markets. The effect of consolidation on quality was mixed whereas there was no evidence of cost reduction or clinical gains from physician- hospital consolidation.

A 2006 report concluded that increases in hospital concentration invariably led to an increase in hospital prices often up to $20 \%$, which are then passed on to consumers in the form of higher premiums and out of pocket costs [13]. A price increase of 6-10\% was noted in a study of 500 hospital mergers between 2000 and 2012 occurring in the same state but different local markets (cross market mergers) [14].

\section{Does M\&A Improve Quality of Care?}

Another reason put forward by health systems is that by treating patients with diseases in high volume hospitals, outcomes may be improved [15]. Healthcare economists who favor competition point to data demonstrating lower costs and improved quality of care with competition [12].

In markets in the U.S and the U.K where prices are determined by a government payer (Medicare and National Health Services, respectively), the conclusion appears to support the improvement of quality with competition [16]. When the market determines price for health care, the relationship between quality and prices is mixed [17].

Kaul and colleagues analyzed Centers for Medicare \& Medicaid Services (CMS) patient encounters in more than 5,600 individual facilities and 526 healthcare systems in the United States both for-profit and nonprofit organizations [1]. In horizontal health systems with multiple facilities, they did not find a correlation between size and cost or quality of care. They recommend that in order to reduce costs by as much as 30 percent, these hospitals have to standardize administrative and clinical procedures, a hard task, rather than each member facility acting autonomously.

\section{Risks}

Higher profits have resulted from greater regional market power. The risks involved in pursuing M\&A are not trivial. Booz and Company, a major consulting firm, opines that one in five hospitals will start to lose money within two years of a merger and $59 \%$ of acquired hospitals will fail to outperform their peers [2]. The reasons appear to be dissimilar corporate cultures, previously unanticipated problems even after due diligence and an unfocused management. They also point out that M\&A takes an enormous amount of time and the opportunity cost of the time and energy wasted on M\&A is large and could have been avoided. The corporate side of the business often fails to appreciate the difficulty in merging two unique cultures into one entity. Physicians or physician groups, who are employed by hospitals as part of 'vertical integration' and caught in the middle of these mergers, are aware of the dissimilar culture of health systems but have limited options as employees.

\section{Benefits}

To be sure, hospitals certainly are not in the business of losing money unless there were demonstrated benefits to the acquirer as well as the not acquirer. The main reasons advanced include: benefit of the larger scale, lower cost of capital and improved care due to standardization of processes and patient care (Table 1) [18]. In fact, one study shows a $2.5 \%$ reduction in annual operating expense per admission at the acquired hospital [18]. However, the authors of this report point out that the expense per admission did not go down in absolute terms but the increase was $2.5 \%$ lower than comparison hospitals. The report also failed to find any statistically significant improvement in outcomes. Another study by Dranove and Lindrooth looked at two independent hospitals merging into one health system between 1986 and 1996 . They saw a benefit of a $14 \%$ reduction only if the two merged hospitals operated using one not licenses rather than two separate licenses [19].

\section{The Future}

It is becoming clear that since the best opportunities may be behind us, all parties are now re-thinking their future course of action [18]. However, this will not keep some large systems

Table 1 Purported advantage of mergers.

\begin{tabular}{|c|c|c|}
\hline Advantage & $\mathbf{\# 1}$ & $\mathbf{\# 2}$ \\
\hline Cost reduction & Scale (spread expense over patient volume) & Reduce \\
\hline Risk-bearing sharing & Share experiences across network & Savital cost \\
\hline Health plans & Share overhead and cost across network & \\
\hline Quality of care & Size may improve out comes & Standard protocols may improve outcomes \\
\hline Strategic & Bolster market share & Pre-empt competitive forces \\
\hline
\end{tabular}


from poaching smaller systems and trying to strengthen their hold on their referral market. Powerful health systems with influential lobbyists will continue to challenge the FTC in court and seek Congressional assistance to amass market share. As physicians are herded into employment, their voices are being softened with only the consumer and the media left to point to the monopolies being created. One of the ways some physicians have countered the merger of hospitals and large insurers is consolidation in single specialty or multispecialty large groups. This is following the playbook of the insurers in the early managed care era when they used excess hospital capacity to push for lower hospital charges and the current modus operandi of the hospitals merging to gain market power. Market forces have altered the size of physician practices. While the solo or 2-10 physician practices are decreasing, large groups approaching 50 physicians are on the rise. An advantage for merging physician

\section{References}

1 Kaul A, Prabha KR, Katragadda SR (2016) Size should matter: Five ways to help healthcare systems realize the benefits of scale. Price Waterhouse Cooper.

2 Cassels T (2014) M\&A-To What End? Advisory Board: Five Characteristics of Intentional Corporate Strategy.

3 http://www.kaufmanhall.com/about/news/hospital-merger-andacquisition-activity-up-sharply-in-2015-according-tokaufman-hallanalysis

4 Minemayer P (2017) Merger-mania trend continues as Partners plans to acquire Care New England Health System.

5 Creswell J, Abelson R (2013) New laws and rising costs create a surge of supersizing hospitals. New York Times.

6 Ellison A (2016) Healthcare executives expect M\&A to drive growth in 2016.

7 Satiani B (2003) Relevance of federal antitrust statutes to clinical practice. J Vasc Surg 37: 1334-1340.

8 Connor RA Feldman RD, Dowd BE, Radcliff TA (1997) Which Types of Hospital Mergers Save Consumers Money? Health Aff pp: 62-74.

9 Spang HR, Bazzoli GJ, Arnould RJ (2001) Hospital Mergers and Savings for Consumers: Exploring New Evidence. Health Aff 20: 150-158.

10 Antwi AY, Gaynor M, Vogt WB (2009) A Bargain at Twice the Price? California Hospital Prices in the New Millennium. Health Eco Policy 12: 3.

11 Robinson JC, Miller K (2014) Total Expenditures per Patient in groups is that the 'vertical' integration of employed physician and hospitals is often associated with higher prices charged to commercial insurers. Studies show that higher prices are not due to increased utilization, and are then passed on by insurers to patients as increase in premiums, deductibles and co-pays.

So, what is the patient to do? Since almost half of the U.S population get their coverage from their employer, most depend on the leverage exercised by their employer. Unfortunately, their out of pocket costs continue to rise due primarily to very high deductibles. The average deductible has risen from $\$ 303$ to \$1,077 between 2006 and 2015 according to the Kaiser Foundation [20-22]. Therefore, the evidence so far is mixed and there appear to be more negatives associated with mergers than positives. The bad news is that with a stalemate, consumers will expect the federal government to step in with centralized control and create further market inefficiencies.

Hospital-Owned and Physician-Owned Physician Organizations in California. JAMA 312: 1663-1669.

12 Gaynor M, Town R (2012) The impact of hospital consolidationUpdate.

13 Vogt WB, Town RJ (2006) How Has Hospital Consolidation Affected the Price and Quality of Hospital Care? The Synthesis project, Robert Wood Johnson.

14 Baicker K, Chandra A (2006) The Labor Market Effects of Rising Health Insurance Premiums. J Labor Eco 24: 3.

15 Dafney L, Ho K, Lee RS (2016) The Price Effects of Cross-Market Hospital Mergers.

16 Cutler DM, Scott Morton F (2013) Hospitals, market share, and consolidation. JAMA 310: 1964-1970.

17 Gaynor M, Moreno-Serra R, Propper C (2010) Death by Market Power: Reform, Competition and Patient Outcomes in the National Health Service. Ame Eco J Eco Policy 5: 134-166.

18 http://www.rwjf.org/en/library/research/2012/06/the-impact-ofhospital-consolidation.html

19 Evans M (2016) Merger indigestion. Mod Healthc 46: 16-18.

20 Noether M, Mat S (2017) Hospital Merger Benefits: Views from Hospital Leaders and Econometric Analysis. CRA.

21 Dranove, David and Richard Lindrooth (2003) Hospital consolidation and costs: another look at the evidence. J Health Econ 22: 983-997.

22 Claxton G, Levitt L, Long M (2016) Payments for cost sharing increasing rapidly over time. Peterson-Kaiser health sys tracker. 